Cita bibliográfica: Rodrigues Ferreira, D. I. y . Sánchez Martín, J. M. (2020). La agricultura como producto turístico en áreas rurales: Un debate abierto en la literatura. Investigaciones Turísticas (20), pp. 97-123. https://doi. org/10.14198/INTURI2020.20.05

\title{
La agricultura como producto turístico en áreas rurales: Un debate abierto en la literatura
}

\section{Agriculture as tourism product in rural areas: A debate that remains open literature}

Dora Isabel Rodrigues Ferreira iD, Universidad de Extremadura, España

drodrigucc@alumnos.unex.es

José Manuel Sánchez Martín iD, Universidad de Extremadura, España

imsanche@unex.es

\section{RESUMEN}

La agricultura, como producto turístico, se basa en una diversidad recursos que permiten múltiples usos, de lo que deriva un enorme potencial de desarrollo para las áreas rurales. Destacan el patrimonio colectivo, el paisaje agrario y el entorno rural, además del rico patrimonio gastronómico donde los productos agroalimentarios y el vino son indisociables de su historia e identidad. La oportunidad de participar en tareas agrícolas y contactar con los agricultores puede ser factible con la puesta en marcha del agroturismo, aunque ese producto no debe desvincularse del entorno rural. Las conclusiones presentadas se basan en un análisis sistemático de la literatura, buscando algunas orientaciones para la realidad de Portugal y España.

Palabras clave: Paisaje agrícola; turismo gastronómico; agroturismo; turismo rural.

\section{ABSTRACT}

Agriculture, as a tourism product is based on a resource diversity that enables different uses and contributes to the development of rural areas. Particularly noteworthy is the collective heritage of rural areas, especially the agrarian and rural landscapes and the gastronomic specificities as the agri-food products and wine are inseparable from the local identity and culture. The opportunity to participate in agriculture activities and to bring farmers and tourists closer together may be viable with the implementation of an agritourism activity. However, this product should not be disconnected from the rural environment. This study is based on a systematic literature review and the main conclusions indicate some orientations for the Portuguese and Spanish reality.

Keywords: Agriculture landscape; gastronomic tourism; agritourism; rural tourism. 


\section{INTRODUCCIÓN}

La reforma de la Política Agrícola Común (PAC), después de la década de 2000, originó un cambio significativo de las políticas de desarrollo rural, creando e implementando incentivos a la multifuncionalidad agrícola y reforzando su función como marca identitaria e hito del futuro de los espacios rurales (Kiryluk-Dryjska y Baer-Nawrocka, 2019). Se incide en la protección de paisajes y ecosistemas, así como en la revalorización de las relaciones sociales y culturales de estas áreas, en particular, las marginales y con estructuras de producción agrícola fragmentadas (Cavaco, 2005). Consecuentemente, surgen nuevos paisajes productivos que alteran los patrones de la ruralidad, marcados por nuevas culturas, estructuras, equipamientos y cambios en la configuración de los asentamientos rurales. Los nuevos patrones de la estructura económica se basan en actividades transversales y complementarias a la agricultura, como sucede con las industriales, la artesanía típica (Belova y Kropinova, 2015; Brunori y Rossi, 2007), la recuperación del patrimonio cultural y paisajístico (Cassia et al., 2015), la revalorización de los productos típicos (Riguccio et al., 2015), hasta el propio turismo rural (Hjalager, 1996). Por un lado, se encuentran áreas con una agricultura "viva", que mantienen o incluso aumenta su competitividad, aunque por otro, hay espacios donde la actividad agraria disminuye e incluso desaparece, como defiende Molinero (2011:5) "solo perviven en el recuerdo, representados en las obras de arte o cantados y evocados por el pueblo".

Tanto Portugal como España se enfrentan a graves problemas demográficos, como el envejecimiento, ya que la población de 65 o más años se sitúa en el $21,7 \%$ y el 19,2\%, respectivamente ${ }^{1}$. A ello se une un intenso despoblamiento en buena parte del medio rural, consecuencia de su atraso socioeconómico y la desatención de la administración pública. Ambos fenómenos repercuten en el paisaje agrícola, donde se registra un progresivo debilitamiento de la agricultura como eje fundamental del aprovechamiento productivo de los espacios rurales (Arnalte Alegre y Muñoz Zamora, 2009). Los agricultores que persisten se transforman en empresarios rurales, obligados a realizar actividades complementarias a la agricultura (Cunha, 2004), para hacer frente el desafío de satisfacer los deseos de una sociedad cada vez más urbanita.

En realidad, muchos habitantes de las ciudades buscan el contacto con la vida agraria y rural, como si fuese un "enclave idílico" (Bandyopadhyay y Morais, 2005 en Nazariadli et al., 2018), lo que conlleva la superación de nuevos desafíos. Entre ellos se encuentra la necesidad de buscar productos "auténticos" y de "calidad" a un público que, al mismo tiempo, aspira un reencuentro con sus "raíces" (Streifeneder, 2016), buscando nuevas tendencias de turismo no masificado. Bimonte y Faralla (2012) concluyen que los turistas que valoran los destinos no masificados son los que consumen más productos locales y orgánicos (73\%), quienes más utilizan los restaurantes típicos (62\%) y su preferencia por el agroturismo resulta más evidente (35\%).

El turismo ha desempeñado un papel importante en la configuración de la estructura agrícola al integrar servicios de alojamiento a través del agroturismo (Phillip et al., 2010, Barbieri et al., 2015). Surgen actividades relacionadas con la educación (McGehee, 2007), con

1. Datos INE (2018), disponibles en www.ine.es, consultado en Mayo de 2019. 
la producción de alimentos orgánicos y respetuosos con el medioambiente (Kuo et al., 2008) que ayudan a mantener los paisajes agrícolas. Estos, en virtud de sus estructuras físicas y ecológicas a lo largo de la historia, forman un «paisaje cultural» (Plaza Gutiérrez, 2016), cada vez más demandado (Chen et al., 2016). El Convenio Europeo del Paisaje reconoce los espacios rurales y agrarios como factores clave de la identidad cultural de los territorios, aunque se enfrentan a nuevos desafíos, al ser "la clave del bienestar individual y social y un recurso favorable para la actividad económica y la generación de empleo" (ELC, 2000:1).

El turismo se ha transformado en una fuerza motriz de atracción para las áreas rurales, revalorizando sus tradiciones mediante la diversificación económica (Carneiro et al., 2015). Dichas transformaciones han sido analizadas en numerosas publicaciones que versan sobre los vínculos que se establecen entre agricultura y turismo (Pearce, 1990 Walford; Walford, 2001; Fleischer y Tchetchik, 2005, citados por Randelli et al., 2014) o entre agricultura y paisaje (De Montis et al., 2017; Thompson et al., 2016). Ofrecen diferentes perspectivas de interpretación que desvelan nuevos enfoques del desarrollo rural sostenible basados en la agricultura. Tienen características singulares, al promover la participación de los actores locales, revalorizar los productos locales, preservar el paisaje y conservar las tradiciones rurales. En definitiva, consideran:

- El paisaje que permite al turista el contacto con la naturaleza, en una condición pura e inmaculada, o permitiendo el contacto con las áreas rurales, espacios agrarios y sus paisajes culturales (Aznar et al., 2007), emergiendo patrones de producción respetuosos con el medioambiente (Kuo et al., 2008).

- El agroturismo como forma de turismo sostenible que valora el capital rural y las economías locales (Sznajder et al., 2009), al mismo tiempo que desempeña un papel importante en la educación y recreación con las tareas agrarias (Brandth y Haugen, 2011), importante para preservar la memoria de un modo de vida particular.

- Las tradiciones rurales asociadas a la agricultura, especialmente la agricultura a pequeña escala, que revela la autenticidad del modo de vida rural y el respecto por la naturaleza (Carneiro et al., 2015).

- El patrimonio gastronómico y vinícola que desarrolla un papel importante para el turismo sostenible apelando al deseo de degustar la autenticidad del territorio (Sims, 2009), a la vez que integra al agricultor en la cadena de valor del turismo a través de suministro de alimentos (Anderson, 2018).

\subsection{La dialéctica de las áreas rurales}

Las áreas rurales periféricas son reconocidas como espacios que ofrecen calidad de vida por sus excelentes parámetros ambientales, lo que favorece su aprovechamiento como recurso turístico natural y de autenticidad cultural y social (Figueiredo, 2009). Sin embargo, la proyección de actividades o condiciones necesarias para el desarrollo de las áreas rurales depende de la delimitación y distinción entre diferentes tipologías, para las que se deben diseñar políticas de desarrollo apropiadas (Bański y Mazur, 2016). Para apoyarlas es necesario un consenso que delimite las áreas rurales, realidad que se acomete con la dificultad de definir 
"rural" y "ruralidad", como reflejan algunos estudios (Kayser, 1990; Figueiredo, 2003a, citados por Figueiredo, 2009).

De hecho, se detectan numerosos conceptos, criterios y tipologías que identifican las áreas rurales, partiendo de estudios enfocados al análisis de criterios físicos y económicos del territorio, uso del suelo, baja densidad de habitantes e infraestructuras, paisaje y producción agrícola e incluso de aspectos sociales (Cherry, 1976; Gilg, 1985, 1985; Wibberley, 1972; Kayser, 1983; Cloke, 2003; Woods, 2005 citados por Bański y Mazur, 2016). El mismo estudio refiere que las perspectivas tipológicas diferencian las áreas rurales y urbanas, de acuerdo con la localización geográfica, partiendo de una clasificación entre áreas rurales tradicionales y áreas periféricas. Al mismo tiempo, existen numerosas investigaciones avaladas por organismos internacionales, como la OECD, que hace referencia al indicador de densidad poblacional, fijando el límite máximo de 150 habitantes $/ \mathrm{Km}^{2}$ para las áreas predominantemente rurales (APR; OECD, 1994; citados por Madureira et al., 2013).

La "cuestión rural" reaparece en España con la Ley no45/2007 de 13 de diciembre para el Desarrollo Sostenible del Medio Rural, donde se establece que los territorios rurales se definen de acuerdo con diferentes nomenclaturas", reflejo de una realidad "rural" diversa, donde se identifican zonas rurales "a revitalizar, intermedias y periurbanas", para las cuales se requiere un tratamiento diferenciado. Mientras, en Portugal, la Ley 48/98 de 11 de agosto que define las Bases de la Política del Ordenamiento del Territorio e del Urbanismo, clasifica los territorios según la aptitud del suelo. Distingue el suelo rural del urbano por su vocación para las actividades agrícolas, pecuarias, forestales, mineras o de espacios naturales de protección, cuya estructura espacial y clasificación se define a través del Plan Director Municipal. Sin embargo, para fines estadísticos se utilizan las nomenclaturas territoriales designadas por Tipologías de Áreas Urbanas (TIPAU 2017), que clasifican el territorio en áreas predominantemente urbanas (APU), áreas medianamente urbanas (AMU) y áreas predominantemente rurales (APR), de acuerdo con criterios como la densidad de población y de ordenación del territorio ${ }^{3}$.

La clasificación de áreas rurales en el contexto europeo depende de los criterios que establece cada país. A pesar de la diversidad de instrumentos y criterios existentes entre Portugal y España, el más común es la densidad de población inferior a los 100 habitantes por $\mathrm{km}^{2}$. Con ese criterio, en España, las áreas rurales representan $85 \%$ del territorio, donde reside el $20 \%$ de la población total (Gobierno de España, 2018), mientras que en Portugal, representa al $12 \%$ de la población que vive en el $65 \%$ del territorio (INE, 2018b) 4 .

2. a) Medio rural - el espacio geográfico formado por la agregación de municipios o entidades locales menores definido por las administraciones competentes que posean una población inferior a 30.000 habitantes y una densidad inferior a los 100 habitantes por km2; b) Zona rural - ámbito de aplicación de las medidas derivadas del Programa de Desarrollo Rural Sostenible regulado por aquella Ley, de amplitud comarcal o sub provincial, delimitado y calificado por la Comunidad Autónoma competente; c) Municipio rural de pequeño tamaño - el que posea una población residente inferior a los 5.000 habitantes y esté integrado en el medio rural.

3. a) Tipología de suelo no urbano; b) Espacio geográfico con densidad de población igual o inferior a los 100 habitantes por km2; c) No integrar territorios con población residente igual o superior a los 2000 habitantes.

4. Datos INE (2018), disponibles en www.ine.pt, consultados en Mayo de 2019. 
A pesar de que los conceptos y delimitaciones territoriales de las áreas rurales son variables, sus desafíos son comunes. Se enfrentan a cambios debidos al despoblamiento demográfico y territorial, a la caída de la población en edad activa, al envejecimiento y al abandono de la actividad agrícola. Pese a ello, estas áreas también son espacios de llegada de la llamada "generación soporte" (Camarero, 2009), principal pilar de la vida rural. Se trata de la generación activa, dedicada a la producción, recuperación y preservación del medio rural tradicional a través de emergentes e innovadoras actividades relacionadas con agricultura, la cultura y la dinamización turística (Madureira et al. 2013), aprovechando su potencialidad y competitividad, donde el medioambiente y sus atractivos son los principales recursos para su actividad, al mismo tiempo que se benefician de las infraestructuras y de las nuevas tecnologías para desarrollar otros modelos de negocio.

La dialéctica de las áreas rurales está marcada por diferentes conceptos, tipologías y criterios de delimitación, pero también por diferentes políticas y estrategias que apuestan por el desarrollo rural. Pese a la importancia de la actividad agrícola en los territorios rurales, Núñez Ferrer (2009) enfatiza que no es suficiente para el desarrollo rural, reforzando la necesidad de promover una agricultura más sostenible y responsable, proteger el medioambiente y apostar por la diversificación de actividades, especialmente el turismo.

En este sentido, cabe señalar que la legislación española reconoce la importancia del turismo en espacios rurales como una actividad de diversificación económica. Recomienda "fomentar el turismo rural, en particular a través de una adecuada ordenación de la oferta y la mejora de la demanda turística, con una atención preferente al fomento de un turismo sostenible en las zonas rurales prioritarias, y al agroturismo o turismo ligado a la actividad agraria" (Ley 45/2007, de 13 de diciembre, para el Desarrollo Sostenible del Medio Rural, art. 20, apartado e). En Portugal, se ha reconocido recientemente la importancia de los agricultores a través del Decreto-Ley n.o 9/2019 de 18 de enero, que define el estatuto del "Joven Empresario Rural", señalando la diversificación de actividades en áreas rurales, la revalorización de recursos locales y las actividades innovadoras y sostenibles como base para el desarrollo de dichos territorios. A ese respecto, Covas (2011), refiere que es imperioso promover el "triángulo virtuoso entre agricultura, ambiente y turismo rural" basado en un modelo agrorural que busca la estética paisajística, la ética de la ordenación del territorio y la gestión agroecológica de los recursos naturales, llamando la atención sobre la necesidad de "elegir la dosis adecuada de agricultura, ambiente y turismo", a modo de hipótesis "ecotópica". Lo mismo refuerzan los autores Moltó Montero y Hernández Hernández (2004) al considerar que el papel de las políticas de desarrollo regional tienen que atentar en las funciones de actividad agrícola, pues es la actividad que suporta los paisajes rurales, el paisaje que es importante mantener, preservar y valorar, dado que puede generar "externalidades para las actividades turísticas pero además puede generar una serie de productos de calidad, demandados no sólo por consumidores cada vez más exigentes, sino incluso por los propios visitantes, atraídos por producciones típicas del área visitada" (Moltó Montero y Hernández Hernández, 2004: 73). 


\subsection{Tendencias y características de la oferta y la demanda del turismo rural}

\subsection{1. ¿Crisis o crecimiento del turismo rural?}

El concepto de turismo rural se basa en criterios geográficos y en la especificidad de la oferta vinculada al modo de vida rural y al aprovechamiento de los recursos locales (Luís, 2002), aunque su concepción es diferente en Portugal y España. En Portugal se adopta la designación de "Turismo en Espacio Rural" que tiene un conjunto de modalidades: "Agroturismo", "Turismo de Aldea", "Casas de Campo" y "Hoteles Rurales" (Diario de la República, 1.a serie - N. .160 - 20 de Agosto de 2008). En cambio, España carece de una normativa nacional que regule los "Alojamientos de Turismo Rural", lo que incide en una diversidad de tipologías, que varían de unas comunidades a otras, por lo que los datos del INE (2018), relativos al tipologías del "Alojamiento de Turismo Rural", que incluyen "Hoteles Rurales", "Apartamentos Rurales" y "Casas Rurales", son transmitidos por cada comunidad en función de sus variedades.

Durante la última década se ha producido un crecimiento significativo del turismo rural en ambos países, tanto del lado de la oferta, como de la demanda, lo que resulta interesante para el desarrollo de productos turísticos en destinos no masificados. Además, se ha producido un crecimiento en la cantidad, variedad y calidad de los recursos susceptibles de aprovechamiento turístico transformando la estructura productiva del mundo rural (Pulido Fernández y Cárdenas García, 2011).

En España, durante el primer semestre de 2019 había registrados 17.685 establecimientos, lo que indica un fuerte crecimiento, ya que en 2008 existían 12.794 establecimientos abiertos. La oferta disponible varía en todo el territorio, aunque destacan Castilla y León y Andalucía, que acaparan el $20 \%$ y el $14 \%$ de los establecimientos respectivamente. En territorios fronterizos, especialmente Extremadura, la oferta supone aproximadamente el $4 \%$. La capacidad actual se estima aproximadamente en 173.000 camas, de las que el 4,5\% están en Extremadura ${ }^{5}$.

Por su parte, Portugal, de acordó con los datos disponibles, durante 2017 registraba 1419 alojamientos de "Turismo en Espacio Rural y Habitación" (INE, 2018), un 50\% más desde 2012. Las estadísticas oficiales presentan la oferta según la tipología del alojamiento, donde el "Agroturismo" tiene un peso de 16,2\% (230 unidades) ocupando la segunda posición de la tipología de alojamiento en espacio rural, seguido de la tipología "Casas Rurales" (45\%), que representa el 16,6\% de la capacidad total (INE, 2018). La oferta de la tipología del "Agroturismo" registra un evolución de 47\% desde el año de 2001 segundo los datos presentados en Luís (2002).

Se observa como el turismo vinculado a la agricultura o a los productos agroalimentarios aumenta a nivel global, tal como se recoge en experiencias de diferentes países como Costa Rica (Blanco y Rivero, 2010); Brasil (Goulart y Tulla, 2015); México (Torres, 2003); Escocia (Flanigan et al., 2014); Croacia (Pavletic, 2015); Australia (Duarte Alonso, 2010); España (Armesto y Gómez, 2006); o Turquía (Sengel et al., 2015); o Sudáfrica (Pillay y Rogerson, 2013).

5. Datos INE (2019), consultados en www.ine.es, disponibles en Mayo de 2019. 


\subsection{2. ¿Qué busca la demanda?}

La demanda comienza a decantarse por las ofertas de "experiencias", donde se evalúan viajes activos y ricos en emociones, buscando una variedad de actividades que le permitan el contacto con la historia, cultura, ambiente y poblaciones (Kastenholz et al., 2012). Por ello, la tendencia actual consiste en buscar oportunidades para realizar actividades con las que tener gratas experiencias a través del contacto directo y próximo con los destinos naturales y rurales, especialmente para aquellos turistas más informados y con una visión consciente del impacto turístico. El turista considera en su decisión el encuentro con la población local, las oportunidades de aprendizaje, además del disfrute que puede proporcionarle el territorio (Ramírez, 2015).

En Portugal aumenta la demanda de alojamiento de "Turismo en Espacio Rural y Habitación", segmento que alcanzó en 2017, aproximadamente 795.000 huéspedes (+19\% respecto a 2016) y 1.700 .000 pernoctaciones (+17\%). Pese a este incremento, el turismo rural representa únicamente el $4 \%$ de la demanda. Las tipologías "Casas de Campo" y "Hoteles Rurales" son las que registran más pernoctaciones, $43 \%$ y $23 \%$, respectivamente. En cambio, el agroturismo acapara el $15 \%$ de ellas en la modalidad "Turismo en Espacio Rural y de Habitación", aunque con una tendencia creciente durante los últimos años (INE, 2018). Las regiones Norte y Alentejo son las que tienen mayor demanda de "Agroturismo", y son importantes para los mercados de España y Francia, que se refleja también en la región Centro.

En España, se registran aproximadamente 853.000 pernoctaciones en "Alojamientos de Turismo Rural", con más de 307.000 viajeros, de los que el $65 \%$ y el $73 \%$ son nacionales. La estancia media es reducida, apenas 2,32 días, aunque en Andalucía llega a 3,24. (Sayadi y Calatrava-Requena, 2001), revelaron que el perfil del visitante más interesando por el agroturismo corresponde a una persona relativamente joven (entre 25-45 años de edad), con nivel de estudios medio-alto, que vive en zonas urbanas y metropolitanas y sin raíces familiares agrarias.

\subsection{Significado y definición de producto turístico agrícola}

Los componentes tangibles e intangibles son inherentes a la actividad turística, de los que derivan numerosos servicios, productos y experiencias. El producto está compuesto por los atractivos (historia, personas, cultura, clima, paisajes, entretenimiento, actividades, etc.), las infraestructuras (alojamiento, comida, etc.) y los sistemas de soporte (transportes, comunicación, canales de venta, etc.) pudiendo definirse como "producto turístico" todo lo que el turista utiliza, consume, adquiere o realiza durante su viaje (Jeffries, 1990, Burkart y Medlik, 1981, citados por Fawcett, 1996). Smith (1994), aún le añade el marco físico del territorio, los servicios, la hospitalidad, la libertad de elección del turista y su implicación en la elaboración y reafirmación del producto turístico.

El turismo basado en la agricultura comprende, según Shaw y Williams (1994), citado por Randelli et al. (2014) , el alojamiento y las actividades en fincas o explotaciones agrícolas, mientras que Davies y Gilbert (1992) lo segmenta en tres categorías: alojamiento, actividades y visitas diarias. Por su parte, Clarke (1996) presenta los elementos del turismo basado en la 
agricultura, identificando las atracciones y actividades, entre las que contempla el contacto con la naturaleza y las visitas a espacios naturales, así como los accesos, el alojamiento y las atracciones rurales. La interpretación de Clarke (1996) lo vincula al agroecoturismo, ya que integra agricultura y naturaleza (Kuo et al., 2008).

A pesar de que los estudios que consideran la agricultura como producto turístico son escasos, es posible identificar las partes que lo configuran, principalmente, los recursos, actividades y servicios (Tabla 1 ).

Tabla 1. Productos, actividades y servicios turísticos basados en la agricultura

\begin{tabular}{ll}
\hline Recursos & Paisaje agrícola \\
& Productos agrícolas \\
& Gastronomía y Vino (productos tradicionales) \\
& Cultura y tradiciones locales \\
& Centros de visitas agrícolas \\
& Senderos agrícolas \\
& Patrimonio rural y patrimonio agrícola (tangible e intangible) \\
& Áreas de conservación natural vinculadas a explotaciones agrarias \\
\hline Actividades & Senderismo en contextos de paisajes agrícolas \\
& Observación e identificación de flora \\
& Rutas gastronómicas \\
& Degustaciones alimentarias o de vino \\
& Talleres de cocina tradicional \\
& Participación en tareas agrícolas \\
& Tareas de cuidado con animales \\
& Demostraciones de cocina tradicional \\
& Demostraciones de tareas agrícolas \\
& Visitas educativas a explotaciones agrarias \\
& Alojamiento y desayuno \\
& Restauración (comedores) \\
& Educación (recreación) \\
& Información (folletos, catálogos, turismo digital) \\
\hline Servicios &
\end{tabular}

Fuente: adaptado de Clarke, 1996; García, 2005; Gao et al., 2013; Thompson et al., 2016; Cassia et al., 2015.

\section{OBJETIVOS Y METODOLOGIA}

Este artículo pretende realizar una reflexión que apunten direcciones para la concepción de productos turísticos que tengan la agricultura como eje central de desarrollo de ofertas concretas en áreas rurales. Su análisis comprendió una revisión sistemática de literatura, considerando artículos de los últimos 30 años que expliquen el papel de la agricultura, por lo que se plantea un breve bosquejo sobre las tendencias que pueden originar las especificidades del producto o productos turísticos derivados de la actividad agrícola, especialmente aquel basado en el paisaje, las tareas agrarias o el agroturismo, las tradiciones agrarias y rurales y la gastronomía y vino, con el fin de comprender su relevancia en el desarrollo de las áreas rurales ibéricas. 


\section{AGRICULTURA Y TURISMO. UNA FORMA DE APROVECHAR SINERGIAS}

\subsection{El paisaje agrícola como producto turístico}

El paisaje es la interfase entre naturaleza, cultura, herencia tangible e intangible, así como los reflejos de la biodiversidad biológica y cultural de los territorios (Rössler, 2006, citado por Assandri et al., 2018). De forma específica, el paisaje agrícola alberga ecosistemas naturales que sustentan medios de subsistencia y bienestar, que actúan como reguladores del clima, conservan el suelo y el agua, a la vez que suministran y conservan el hábitat de muchas especies (Dou et al., 2019). Para Davis y Corsane (2014), el paisaje agrícola es un auténtico "museo a cielo abierto" que representa la cultura local, considerada por Carneiro et al., (2015) como el elemento más importante de la experiencia turística en áreas rurales.

Desde la óptica del turismo, destaca la importancia del paisaje como atractivo para los entornos rurales y agrícolas (Lane, 1994; Daugstad, 2008; Sznajder et al., 2009, citados por Thompson et al., 2016), resaltando las prácticas de baja intensidad asociadas a sistemas que promueven la resiliencia de los ecosistemas, a su belleza y a su valor paisajístico (Daniel et al., 2012).

Si se entiende el paisaje agrícola como un producto turístico y como un importante recurso para desarrollar la actividad turística en áreas de baja densidad demográfica, es necesario identificar los elementos que lo componen, así como conocer las interrelaciones existentes con el sistema turístico (Duarte Alonso, 2010). Su comprensión es vital para fundamentar los vínculos entre los actores rurales, con el objetivo de potenciar experiencias completas y capaces de atraer turistas.

La complejidad de los paisajes agrícolas, moldeados por múltiples factores, ha provocado que algunos autores dividieran los paisajes en tres categorías diferenciadas (Urry, 1990, 2002, citados por Thompson et al., 2016; Gao et al., 2013) que, consecuentemente, tienen un fin turístico:

- Naturalscape, denominada como paisaje natural, que incluye los elementos biofísicos (geología, formas de relieve, tipos de suelo, clima e hidrología) y la biodiversidad (flora y fauna), además de los ecosistemas y hábitats específicos de áreas no productivas (humedales, bosques).

- Farmscape, definida como paisaje agrícola, que incluye las explotaciones agrarias, (cultivos, secano...) o ganaderas y demás explotaciones agrícolas como huertos, praderas, viñedos, olivares tradicionales o dehesas. Representa el uso agrícola.

- Culturescape, que incluye los recursos culturales que resultan de la interacción entre naturaleza y ambiente, expresados por las características de los asentamientos rurales y toda la componente sociológica, desde costumbres, palabras o expresiones típicas a infraestructuras como senderos, paredes de piedra y zonas de almacenamiento (graneros) o de procesado (molinos). 
Gráfico 1. Componentes del paisaje agrícola para uso turístico

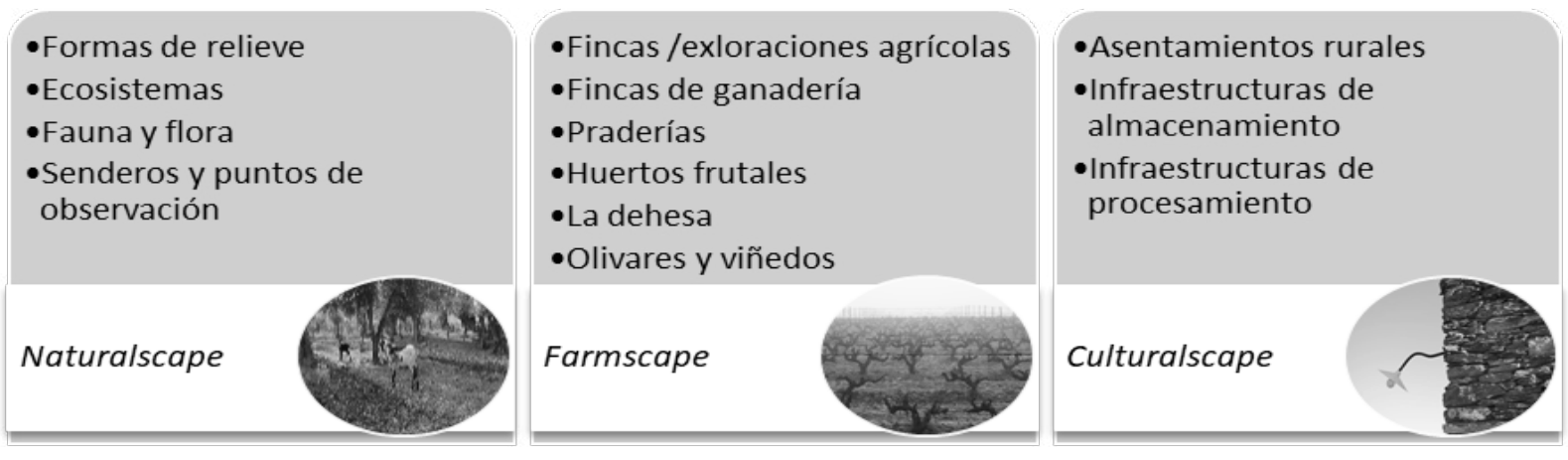

Fuente: adaptado de Thompson et al., 2016.

El paisaje agrícola incluye fincas, explotaciones agrícolas y otras tierras (huertos de frutales, praderas, dehesas, cultivos de hortícolas), productos agrícolas (culturas y alimentos) así como infraestructuras de procesado, caracterizados por sistemas de producción convencional. La diversidad de este paisaje moldea su uso recreativo para el senderismo o la observación de aves, como resultado de las sinergias que se establecen entre las prácticas agrícolas y el aprovechamiento recreativo de las áreas de conservación de la naturaleza (Gao et al., 2013).

Salvado (2016) defiende que los conceptos de paisaje, territorio y patrimonio son indisociables, comprendiendo todos los componentes físicos, biológicos y culturales, reforzando la idea de que los paisajes agrícolas son auténticos paraísos para las prácticas turísticas, el disfrute de la gastronomía y la enología, así como para la realización de actividades al aire libre que fomenten el contacto con la naturaleza. Es particularmente interesante para los núcleos rurales que aún preservan la tradición agrícola y sus prácticas ancestrales, pues forman así un "ecomuseo vivo", idóneo para que los turistas lo visiten y experimenten estas tareas tradicionales que realizan los agricultores locales, disfrutando así de una herencia sostenible. Pero es importante notar que la manutención de una agricultura activa es fundamental para conservar los paisajes y notar el papel crucial que los agricultores desarrollan, no solo como productor de alimentos sino también como protector del ambiente (Hernández Hernández y Moltó Mantero, 2000) y al contribuir para los paisajes culturales impresionantes (Carneiro et al., 2015). Destacan estudios de paisajes específicos como los viñedos (Carmichael, 2005; Salvado, 2016; Assandri et al., 2018) y olivares (Duarte Alonso, 2010; Ciervo, 2013; Nekhay y Arriaza, 2016), en los que se concluye que el paisaje es producto turístico que resulta de:

- La conservación de los sistemas de producción tradicionales y la biodiversidad.

- La preservación las características del paisaje, su autenticidad y el carácter de la ruralidad visible en los campos cultivados.

- La importancia de preservar los elementos culturales del paisaje, como muros de piedra, escaleras, senderos, molinos de agua o de viento u otras infraestructuras de apoyo. 
Algunos ejemplos de paisajes agrarios reconocidos por la UNESCO como Patrimonio Mundial son los viñedos del Duero (Portugal) y la Sierra Tramontana en Mallorca (España). Ello se debe a que mantienen las actividades agrarias tradicionales y el aprovechamiento de los viñedos y olivares en su estructura productiva tradicional, así como la preservación de las infraestructuras y la arquitectura paisajística que enmarca la actividad productiva y el entorno rural y tradicional (UNESCO, 2019). Son componentes importantes del paisaje rural y de reclamo para el agroturismo.

A ese respecto, LaPan y Barbieri (2014) concluyen que los turistas señalan su preferencia por la existencia de elementos históricos en el paisaje, mientras Gao et al (2013), opinan que los turistas valoran las características naturales y culturales en el agroturismo, señalado así la importancia del paisaje como recurso turístico.

\subsection{Las tareas agrícolas (y el agroturismo) como producto turístico}

La interacción y participación de los turistas en actividades agrícolas se basa en la premisa de que el agroturismo es un sistema agrícola productivo, auténtico y de contacto directo. Esta tipología comprende las actividades de participación directa del turista en las tareas agrícolas, con la posibilidad de pernoctar en las fincas (Phillip et al., 2010). Permite que los turistas experimenten y comprendan formas de producción y se relacionen con los productos agroalimentarios y ganaderos desde una perspectiva más emotiva y auténtica. Pese a ello, se detectan diferentes niveles de implicación de los turistas en las tareas agrícolas, que van desde los más débiles, cuando se ciñen al alojamiento y el consumo de productos agroalimentarios locales, hasta los más fuertes, que incluyen también la participación activa en las actividades y procesos productivos, la degustación de productos frescos y el contacto directo con los agricultores, donde los productos se entienden como experiencias sensoriales. 
Gráfico 2. Atributos de experiencias en fincas agrícolas según niveles

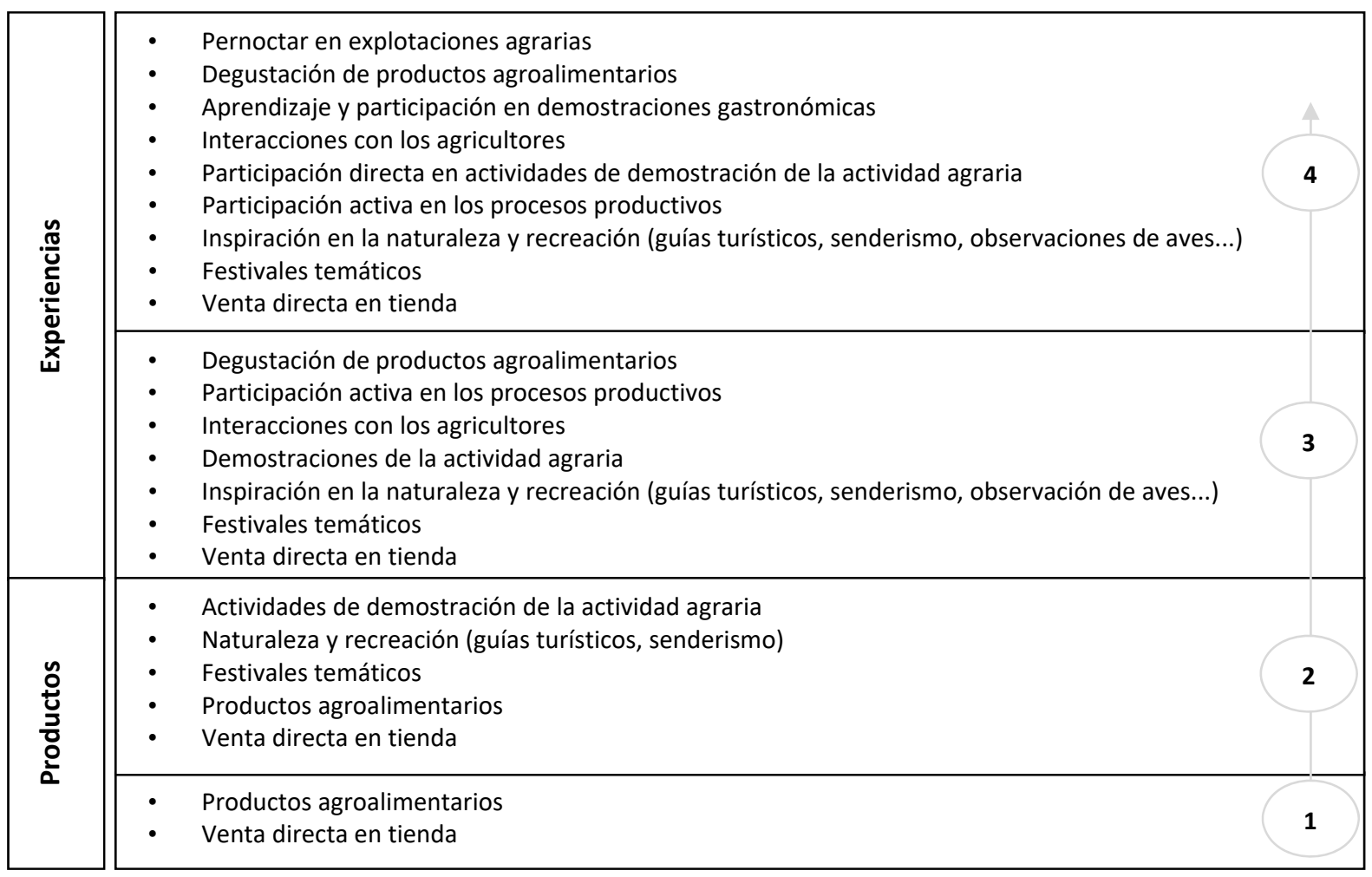

Fuente: adaptado de Comen (2017).

El agroturismo, por tanto, no se limita al contexto de producción orgánica, pues integra otros modos de producción (Hanson y Bell, 2007). No obstante, si se adopta una concepción que asuma los principios integrados en el agroecoturismo es posible que los turistas comprendan mejor, no solo las tareas agrícolas, sino también los valores ecológicos. Las actividades de educación e interpretación ambiental, como el compostaje, la jardinería, la recogida de hierbas aromáticas o el procesado tradicional de alimentos o bebidas, ilustran la relación entre turistas, agricultores y medioambiente, factores distintivos del agroturismo (Ramírez, 2015). Un modelo de este tipo permite que los turistas disfruten de productos más saludables en la restauración o en las fincas y también que participen en eventos especiales con la población local (Kuo et al., 2008). Seguramente este tipo de actividades permite que los turistas muestren mayor interés por los productos agrícolas orgánicos y por el uso racional de los recursos naturales, contribuyendo con ello a una concepción amplia de la sostenibilidad, al incluir en ella el papel educativo.

\subsection{El patrimonio y las tradiciones rurales y agrarias como producto turístico}

El patrimonio rural permite ofrecer "experiencias", "participación activa" de los turistas y admite un encuentro con la "autenticidad" (Buffa y Martini, 2012; Cerquetti, 2012, citados por Cassia et al., 2015). La combinación de patrimonio en su triple vertiente, elementos tangibles, gastronomía y paisaje rural, son los que establecen vínculos más fuertes con la actividad 
agraria y permiten crear ofertas auténticas basadas en las especificidades locales. Brandth y Haugen (2011) concluyen que el patrimonio agrícola, la historia y la cultura de cada explotación agraria es la principal motivación de viaje para los destinos rurales.

El agroturismo preserva el patrimonio agrario y rural, a la vez que recupera la tradición, revestida con patrones de contemporaneidad, "renovado a través de la tradición" (Brandth y Haugen, 2011). A la vez dinamiza el patrimonio tangible, desde los edificios, locales históricos, monumentos, artefactos $u$ otros recursos vinculados a las actividades agrícolas representativas de las tradiciones locales (Barbieri, 2013; Di Domenico y Miller, 2012). Son motivaciones que esgrimen los agricultores que promueven actividades turísticas en sus explotaciones (Cassia et al., 2015; LaPan y Barbieri, 2014) como complemento a la agricultura. Además, la oferta de actividades recreativas en explotaciones preserva el patrimonio familiar, transfiere el saber tradicional para generaciones venideras y permite mantener las costumbres y el patrimonio inmaterial ancestral (Tew y Barbieri, 2012; LaPan y Barbieri, 2014).

Se revaloriza el patrimonio rural mediante iniciativas de promoción de productos agroalimentarios locales o de platos típicos (Bessiere y Tibere, 2013), a la vez que promueven y salvaguardan el patrimonio cultural de los territorios a través de la gastronomía. También se consigue a través la puesta en valor del paisaje rural, de las costumbres y tradiciones de cultivos específicos de cada territorio (Tew y Barbieri, 2012). Por tanto, el patrimonio agrario y las tradiciones rurales se convierten en productos turísticos mediante ofertas relacionadas con:

- El agroturismo y con actividades de contemplación y vivencia del patrimonio material (edificado, infraestructuras de apoyo agrario, monumentos, muros de piedra),

- Experiencias de contacto directo con los agricultores, que son fuente de conocimiento y de ligazón con la población local, cuya hospitalidad es representativa de sus costumbres y tradiciones que dan cuerpo al patrimonio inmaterial.

- La gastronomía que valora los productos locales y el saber hacer tradicional son también una expresión de patrimonio, muchas veces incluido en experiencias de agroturismo o de turismo rural (Sims, 2009).

Asimismo, es preciso señalar que el patrimonio agrario como producto turístico no se desvincula del paisaje y el entorno rural, pues como indica Brandth y Haugen (2011), sin el contexto agrario el potencial turístico pude estar comprometido, lo que incide en la importancia de los recursos agrícolas para el desarrollo del turismo, en particular en los destinos de baja densidad demográfica.

\subsection{La gastronomía y el vino como producto turístico}

Han aumentado las investigaciones que consideran los sistemas agroalimentarios como recursos turísticos (Sidali, Kastenholz y Bianchi, 2015; Sánchez-Cañizares y López-Guzmán, 2012). En ellos se destaca que la gastronomía y el vino son indisociables, y cuando se promueven como productos turísticos deben garantizar al turista la oportunidad de aprender sobre ellos, apreciarlos y consumirlos, valorando las características, olores y sabores particulares de cada territorio. 
La gastronomía se ha transformado en un pretexto para visitar explotaciones agrarias, buscar un contacto más cercano con los agricultores, así como participar en festivales de comida o vino, saborear platos típicos en restaurantes de cocina regional y frecuentar locales de degustación (Haal, y Sharples, 2003). A la vez, el turista tiene la posibilidad de participar en talleres de cocina, visitar bodegas o queserías, en la vendimia u otras tareas agrícolas (Santich, 2004). Esto se ve avalado por el creciente número de turistas que desean conocer los sabores auténticos y específicos que reflejan las tradiciones de los destinos y, a su vez, tienen una historia por descubrir (Armesto y Gómez, 2006; Uğurlu, 2014).

Durante las últimas décadas ha aumentado el interés por las vivir experiencias gastronómicas auténticas (Sims, 2009; Berno, 2011, citado por Thompson et al., 2016) en las que tanto los productos agroalimentarios como el vino configuran la imagen de los destinos. Ejemplos destacados son:

- La Rioja (España), el Duero en el norte de Portugal o Burdeos (Francia), como destinos para los amantes del buen vino;

- Segovia (España) y Mealhada (Portugal), con los cochinillos y vinos característicos.

- Valle de Jerte (España) y Fundão (Portugal), con las cerezas.

- También, algunos países y regiones se presentan como destinos gastronómicos, basados en comida local y el vino, apelando al deseo de saborear lo auténtico (Michelle Thompson et al., 2016). Cabe destacar los casos de:

- "Toscany Road Trip" (Italia), que apela al disfrute del paisaje bucólico y a la degustación de vinos, quesos y el "mejor helado de Italia".

- Borgoña (Francia), mundialmente conocida por sus vinos, pero también por su bebida típica hecha a la base de champán y grosella (Kir Royale) y su famosa salsa.

- Asturias (España), que tiene como base del patrimonio gastronómico las referencias al "paraíso de quesos", los huevos pintos de Pola de Siero y su sidra.

La gastronomía es un producto turístico que forma parte de la cultura local, en la que se refleja la cultura de un pueblo (Hernández-Mogollón et al., 2015), al mismo tiempo que es una herramienta para el desarrollo de la actividad agrícola (Guzel y Apaydin, 2016), y por eso sus relaciones son muy estrechas. Por lo tanto, la gastronomía no puede ni debe desvincularse de su identidad local, fuertemente influida por las características geográficas, ambientales y culturales, donde se tornan visibles los modos de producción agrícola. Bajo esa óptica, la gastronomía y vino se consideran productos turísticos, que desarrollan vínculos más fuertes o más débiles con las prácticas turísticas, dependiendo de la motivación del viaje. Este puede tener como objetivo único la visita a restaurantes porque están en ruta, o tener experiencias más completas con el territorio y su población a través de la degustación de productos y platos emblemáticos y participar en procesos de producción o transformación, algo posible si se cuenta con la interacción de los agricultores (Gráfico 3). 
Gráfico 3. Vínculos entre el turismo gastronómico y su relación con la actividad agrícola

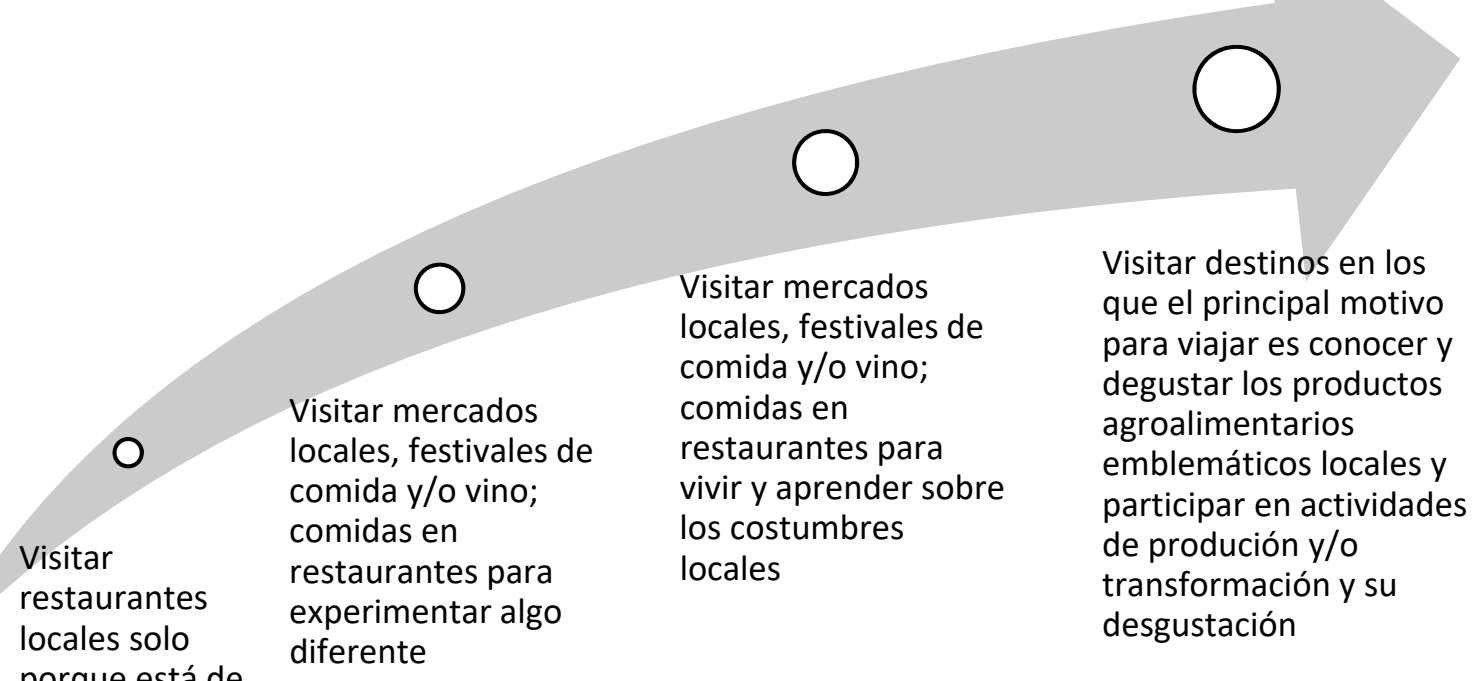

Fuente: basado en Hall y Sharples (2003).

Los productos turísticos relacionados con la gastronomía fueron considerados por Armesto y Gómez (2006) como una estrategia desarrollada para diversificar e innovar la oferta adaptada a la diversidad de motivaciones de la demanda. Para ello, clasificó los recursos en:

- Rutas temáticas - itinerarios de explotación de paisajes agrícolas en torno a productos o platos específicos. Incluye actividades de experimentación, visitas guiadas a fincas, bodegas o unidades de transformación, además de visitas a mercados locales. Son, a título de ejemplo, ampliamente conocidas las rutas del vino en la Rioja, Duero o Burdeos.

- Eventos temáticos - Incluyen festividades tradicionales que celebran las costumbres y productos típicos. Como ejemplos pueden mencionarse los eventos que celebran en Galicia con mejillones o pulpos, o la Gran Fiesta de la Calçotada en Catalunya.

- Viajes a destinos conocidos por sus especialidades gastronómicas - En los destinos existe una gran variedad de restaurantes que utilizan los productos agroalimentarios locales como los principales atractivos del turismo, aunque incluye elementos culturales y naturales para completar la experiencia. Son conocidos los casos de viajes estacionales (durante el otoño para disfrutar de setas del campo en los Pirineos o la lamprea durante la primavera en Galicia) y viajes durante todo el año (cochinillos de Segovia).

\section{DISCUSIÓN}

Existen estudios que estiman la demanda de bienes y servicios no comerciales generados por la agricultura, como sucede con el paisaje, los espacios naturales (Gómez-Limón y 
Barreiro-Hurlé, 2007) o los sistemas agrarios (Sayadi y Calatrava-Requena, 2001), con el turismo rural y el agroturismo, la conservación de la biodiversidad (Barreiro et al., 2003) y la conservación del suelo (Colombo y Calatrava, 2004). Los sistemas agrarios desarrollan funciones de diversa índole que van más allá de su papel productivo, en línea con su multifuncionalidad, convertida en el nuevo paradigma de la PAC tras la reforma de la Agenda 2000 (Massot, 2003 y 2004). Todo ello se refleja en las funciones de la agricultura (productos agroalimentarios), las recreativas (agroturismo) o las estéticas (agro paisaje) (Sayadi y Calatrava, 2001). Dicha perspectiva fundamenta la idea de que los vínculos entre agricultura y turismo son muy estrechos y que la relación entre turistas y agricultores produce beneficios mutuos y con impactos para las comunidades locales y en la estructura económica de los espacios rurales. No obstante, eso no es más que un indicador de esperanza para los destinos rurales para lo cual es necesario diseñar productos capaces de atraer inversiones, visitantes y la llamar la atención pública sobre las singularidades y potencialidades de buena parte de estos territorios.

Las características del mundo rural, unidas a las prácticas agrícolas tradicionales basadas en los principios de la sostenibilidad que combinan campo y naturaleza, constituyen una tipología diferente y holística del turismo en áreas rurales, por lo que existe una oferta de productos distintos y de valor añadido para la demanda. En este sentido, la oferta no se limita a visitar espacios protegidos o a participar en las actividades agrícolas, sino que persigue disfrutar de la biodiversidad o la gastronomía local, considerando el binomio producción-consumo.

Cuando el desarrollo turístico se basa en los valores característicos de la población local y se centra en las raíces del territorio, es capaz de diferenciarse en un mercado globalizado, ofreciendo así productos singulares.

A pesar de todo, resulta difícil encontrar referencias que traten la agricultura como producto turístico, aunque es posible diferenciar dos tendencias claras de estudios que analizan los vínculos que se establecen entre los dos sectores: los que tratan sobre los impactos generados por el desarrollo del turismo en la agricultura (Hermans, 1981; Torres, 2003; Torres y Momsen, 2004; Choenkwan et al., 2016) y los que se ocupan de la influencia que tiene la agricultura en el sistema turístico (Duarte Alonso, 2010; Anderson, 2018). También se detectan otros enfoques minoritarios centrados en el desarrollo económico y en la sostenibilidad agraria desde una perspectiva "agroecológica" como base del agroecoturismo (Kuo et al., 2008), e incluso los que hacen referencia a la multifuncionalidad de la agricultura (Brandth y Haugen, 2011) y de las áreas rurales (Aznar et al., 2007) con el aprovechamiento de los recursos agrarios y rurales para el turismo.

En una época en la que el interés por las experiencias genuinas aumenta (Berno, 2011, citado por Thompson et al., 2016), el turismo adquiere una nueva dimensión al vincularse con la agricultura mediante productos agrícolas locales, considerados como marcadores culturales de "identidad local" y de "identidad paisajística" (Riguccio et al., 2015). También a través de la posibilidad de difundir conocimiento sobre sistemas agrícolas tradicionales favoreciendo el contacto con los espacios productivos, con las raíces culturales y con los agricultores. Esas tendencias expresan que las relaciones entre producto agroalimentario, espacio de producción (agrícola y su transformación por métodos tradicionales) y paisaje son cada vez más estrechas. Quizá por eso, sea más difícil definir la frontera entre las diferentes tipologías de turismo 
existentes en áreas rurales, donde la actividad agrícola tiene un papel determinante en la definición del producto turístico. Si por un lado, el agroturismo es reconocido como la tipología más vinculada a la agricultura (Petroman y Pet, 2017; Comen, 2017; Hüller et al., 2017), por otro, existen otras visiones que atribuyen al turismo rural genérico una oportunidad para mantener el contacto directo con los espacios de producción agrícola y procesado de productos agroalimentarios o simplemente para disfrutar de ellos (Hashimoto y Telfer, 2010; Randelli et al., 2014). A este respecto, Streifeneder (2016) Ilama atención sobre las mezclas conflictivas y adulteradas de términos que pueden desvirtuar el concepto del agroturismo auténtico, entendiendo este como aquel que promueve el contacto con la actividad agrícola, el disfrute de los productos agrarios trasformados en momentos gastronómicos, el aprendizaje y el contacto directo con la naturaleza y los valores sociales del territorio. En esa secuencia, se advierte sobre la oportunidad que tiene la agricultura para convertirse en producto turístico a través del agroturismo (Barbieri et al., 2016), que se presenta como una oportunidad recuperar y revalorizar el patrimonio (Cassia et al., 2015) e incluso ofrecer productos agroturísticos más sostenibles (Barbieri, 2013; Mastronardi et al., 2015).

Resulta difícil identificar la frontera entre los conceptos de agroturismo y turismo rural (Barbieri et al., 2015), al mismo tiempo que se detectan diferentes tipologías entre países y regiones, como sucede en el caso portugués y español, siendo este último mucho más complejo por su casuística territorial. No obstante, existe cierto consenso cuando se entiende el agroturismo como la única tipología que tiene la agricultura como recurso base, manifestándose en actividades y servicios variados. Entre ellos se encuentran el alojamiento en explotaciones agrarias activas, la interacción con los agricultores o el aprendizaje y la participación en actividades agrarias, entre otros.

A pesar de que el agroturismo es la tipología que mantiene relaciones más estrechas con la agricultura, hay evidencias de que el turismo rural, al revalorizar paisajes agrícolas y fomentar el contacto con tradiciones y poblaciones locales se encuentra en una relación tenue con la agricultura. Ello puede ser un indicador que revela la agricultura como base del turismo y que se muestra en múltiples usos y formas de consumo. De modo indirecto, la literatura refleja que los productos agroalimentarios están en la base del turismo, ya que parte de los gastos turísticos se hacen en alimentación (Torres, 2003; Wang et al., 2006; Andersson et al., 2017), transformándose en recurso turístico a través de la gastronomía. El turismo basado en la producción local y la gastronomía surge como una tendencia creciente para el desarrollo rural (Hashimoto y Telfer, 2006).

Por su parte, Hjalager (1996) analizó el concepto del turismo rural a través de dos perspectivas: la innovación en las áreas rurales y los productos turísticos basados en los recursos rurales, donde se incluye la "agricultura", la "diversidad de producción agrícola" y la "producción orientada al ocio". La agricultura es, según dicha perspectiva, el principal producto turístico de los territorios rurales siendo el centro del turismo rural. No obstante, existen otras opiniones que consideran que el producto rural y el agroturístico se caracterizan por la agregación de la naturaleza, la historia y las actividades humanas (Wiatrak 1998, Sikora 1999, Gaworecki 2000, citados por Przezb, 2004), generalmente complementado con las "experiencias", mediante aventuras o disfrute del paisaje, del aire fresco, el silencio, la tranquilidad 
(Roberts y Hall 2001) y descubierta del patrimonio (Sims, 2009), convergiendo la agricultura en un producto que agrega diferentes recursos turísticos basados en los atractivos rurales.

Pese a reconocerse la importancia de la gastronomía y de los productos típicos como recursos turísticos, escasean los análisis sobre las cadenas de suministro establecidas entre los agricultores y el sistema turístico, especialmente en territorios donde la densidad de actores locales es más débil, aunque mantienen un papel importante en la innovación rural, mejorando la red y revalorizando las tradiciones (Madureira et al., 2013). En tal sentido, sería preciso conocer esta trama de actores e identificar los fenómenos de innovación existentes en los destinos rurales marginales, especialmente desde el respeto por los valores agroambientales. De ese modo se podría conocer cómo se puede conseguir la sostenibilidad de la propia actividad agraria, ya sea social, económica o ambiental.

Se pone de manifiesto que la agricultura puede atender a la demanda "más exigente" e informada que busca productos agroalimentarios saludables y sostenibles. Incluso puede generar espacios turísticos que apuesten por la defensa de la biodiversidad y la preservación de valores sociales y culturales representativos de la ruralidad. Aunque sea más orientada a nichos de mercado, puede contribuir al desarrollo de áreas rurales, vinculándose agricultura e industria de procesados con el turismo, promoviéndose una aproximación al "origen" o a la "ruralidad". Estos planteamientos, del desarrollo rural basado en la multifuncionalidad de la agricultura, apoyado por la extensión de la actividad de las explotaciones puede hacer "una importante contribución el empleo regional" (Van der Ploeg y Roep, 2003), aunque esa asociación es todavía muy débil en España y Portugal. La realidad muestra que en España el 23\% de las explotaciones agrarias realizaban actividades no agrarias en 2016 (INE, 2016). En Portugal, solo 4\% de los agricultores de dedican al turismo rural (INE, 2018a). De hecho, se reconoce que las zonas rurales dependen de una base productiva activa, donde la agricultura es un pilar básico, al paso que el turismo, aunque sea importante, no puede de forma aislada generar la competitividad que se ansía para su desarrollo.

\section{CONCLUSIONES}

Tras la revisión de numerosas investigaciones que han tratado los conceptos de turismo rural y agroturismo y la relación existente entre la agricultura y el turismo, especialmente en su visión como producto turístico en el ámbito ibérico, se destacan los retos de desarrollo y competitividad de los sectores tradicionales, en los que la agricultura se manifiesta como recurso poco valorado desde el punto de vista turístico. En esta línea, se concluyen los siguientes aspectos:

- Se observa un crecimiento de la demanda interesada por los productos rurales y las ofertas relacionadas con la actividad agrícola y su multifuncionalidad, la que potencia el turismo, aunque todavía tiene potencial para crecer. Eso requiere atención pública para delimitar las tipologías existentes en las que se confunden conceptos como turismo rural y agroturismo. 
- Los agricultores desconocen las ventajas de vincular su actividad principal con el sistema turístico. Al mismo tiempo, el sistema turístico no mantiene vínculos más estrechos con la agricultura de proximidad.

- Destaca el papel que desempeña el paisaje en la experiencia turística, confirmada por diferentes configuraciones y tipologías, destacándose la importancia de preservar la autenticidad del carácter agrícola y rural, visible a través de los cultivos realizados mediante una agricultura tradicional y sostenible, lo que revela las relaciones positivas que se pueden establecer entre el hombre y la naturaleza.

- El paisaje agrícola como producto turístico asume también la componente cultural en la medida que preservan los edificios y las infraestructuras tradicionales. En ese contexto se centran los estudios que toman como base a los agricultores, auténticos arquitectos del paisaje, cuyo trabajo es vital para garantizar las funciones de producción agraria, así como para la preservación de la naturaleza y del patrimonio histórico y cultural.

- La concepción de la agricultura como producto turístico surge como una oportunidad para los territorios y para los agricultores, ya que permite diversificar actividades, métodos de producción, a la vez que promueven actividades recreativas en las fincas. En ellas aúnan la producción agrícola, el alojamiento, las actividades educativas de contacto directo, el aprendizaje de tareas y sistemas de producción agrícola y el disfrute de los alimentos locales en contextos únicos de proximidad con la naturaleza.

- El contacto directo de los turistas con los agricultores, a través del agroturismo, nunca fue tan importante, ya que hay un vasto conocimiento de ciertos cultivos y técnicas que se están perdiendo. También, porque la población cada vez está más urbanizada y alejada de la base productiva de alimentos, aunque también es exigente con la producción sostenible.

- Aunque los vínculos con la agricultura sean imperceptibles, el turismo gastronómico tiene un potencial de diferenciación para la oferta de productos turísticos en áreas rurales. Es importante salvaguardar que las cadenas de suministro de alimentos sean más próximas entre los agricultores y el sistema turístico. Eso permitirá un contacto más cercano con el sistema agrario, con el conocimiento sobre los productos agroalimentarios y con las raíces y cultura local, que puede revalorizar la oferta.

- El turismo basado en la gastronomía mantiene vínculos fuertes con el agroturismo, ya que promueve el contacto con los productos desde "la tierra hasta la mesa", aunque también los mantiene con el agroecoturismo, un nicho que ofrece prácticas de turismo con impacto positivo para el medioambiente a través de los productos agroalimentarios orgánicos.

- Los lazos que se establecen entre la producción agrícola y los productos agroalimentarios con sello de calidad fomentan el surgimiento de una gastronomía que recupera los métodos tradicionales y más sostenibles, pero capaces de ofrecer productos innovadores.

- El consumo de los productos agroalimentarios permite al turista implicarse en la cultura local, ampliando su experiencia con elementos tangibles. Algunos autores concluyen que los turistas que adquieren productos locales están más satisfechos y tienen mayor probabilidad de repetir el viaje. 
- El patrimonio colectivo, material e inmaterial, de las áreas rurales es indisociable de su historia e identidad por lo que su promoción y revalorización deben formar parte de las políticas de desarrollo rural. Durante los últimos años, esas políticas evolucionaron desde un modelo apoyado en la modernización agraria, debido al desarrollo integrado que potencia el sector de servicios y el turismo rural, hasta un modelo de desarrollo sostenible orientado a mitigar la degradación de los recursos naturales.

- Para que el turismo basado en la agricultura sea posible hay que dar preferencia a políticas de valorización de una agricultura sostenible y responsable. En caso contrario, hay riesgos de desnaturalización de los destinos rurales o del turismo gastronómico.

- Los productos agroalimentarios son el reflejo de la identidad local y se asiste a una necesidad de incrementar los flujos de producción local con el sistema turístico, no solo como instrumento de sostenibilidad, sino también por la disminución de la dependencia externa.

- El agroturismo, como tipología de turismo rural, permite la recuperación y revalorización de tradiciones, técnicas y patrimonio agrario.

- Con el fin de contribuir positivamente y enriquecer la temática sobre la agricultura como producto turístico, a lo largo del trabajo quedó patente la complejidad de un concepto propio que vincule agricultura y turismo. A pesar de ello, surgen tendencias claramente indicativas de un camino que apunta la necesidad de apostar por la sustentabilidad. En ella deben intervenir tanto la oferta como la demanda, permitiendo y favoreciendo el disfrute de los atractivos naturales de flora, fauna, biología, geografía y actividad agropecuaria, compartiendo la cultura, raíces y costumbres locales.

Este trabajo permitió concluir que la agricultura como producto turístico no solo tiene viabilidad como es urgente su valoración a través de ofertas concretas de turismo rural, agroturismo y agroecoturismo. Los vínculos entre agricultura y turismo revelan que es posible innovar a través de nuevos productos agroalimentarios, nuevas formas de consumo o nuevos servicios. Por eso, surgen productos y se revalorizan métodos tradicionales y sostenibles, al mismo tiempo que se potencian ofertas genuinas con experiencias de contacto relacional y emotivo con los destinos. Esto se alcanza mediante el consumo de productos agroalimentarios típicos de cada lugar y con la participación en las prácticas agrícolas, lo que contribuye al disfrute del paisaje agrícola. Obligada es la reflexión acerca del papel de los agricultores, moldeadores de los paisajes, productores de alimentos, prestadores de servicios ambientales y desarrollo de los territorios rurales, por lo que se supone que el turismo es un camino para su reconocimiento de su intervención.

En concreto, las áreas rurales de Portugal y España tienen la oportunidad de poner en valor su potencial agrario al servicio del turismo, contrariando las tendencias del vacío demográfico de las áreas rurales y naturales, valorando conocimiento tradicional e innovando con la oferta de experiencias que vinculen los dos sectores, adecuando las dosis correctas de "agricultura, ambiente y turismo", como son los ejemplos de productos agroturísticos: rutas temáticas que combinan paisaje, relajación, aprendizaje y disfrute de olores y sabores locales. 


\section{REFERENCIAS BIBLIOGRÁFICAS}

Anderson, W. (2018). Linkages between tourism and agriculture for inclusive development in Tanzania. Journal of Hospitality and Tourism Insights, 1(2), 168-184. doi.org/10.1108/ ihti-11-2017-0021

Andersson, T. D., Mossberg, L., y Therkelsen, A. (2017). Food and tourism synergies: perspectives on consumption, production and destination development. Scandinavian Journal of Hospitality and Tourism, 17(1), 1-8. https://doi.org/10.1080/15022250.2016.12752 $\underline{90}$

Armesto, L. X. A., y Gómez, M. B. (2006). Tourism and Quality Agro-Food Products: an Opportunity for the Spanish Countryside. Tijdschrift voor Economische en Sociale Geografie, 97(2), 166-177. Recuperado de https://onlinelibrary.wiley.com/doi/ pdf/10.1111/i.1467-9663.2006.00510.x

Arnalte Alegre, E., y Muñoz Zamora, C. (2009). Desarrollo rural en la Península Ibérica: algunos modelos en el mediterráneo español, En Batista, F., Jacinto, R., y Mendes, T. (Eds.) Os territórios de baixa densidade em tempos de midança, Edición Câmara Municipal de Proença-a-Nova y Centro de Ciência Viva da Floresta

Assandri, G., Bogliani, G., Pedrini, P., y Brambilla, M. (2018). Beautiful agricultural landscapes promote cultural ecosystem services and biodiversity conservation. Agriculture, Ecosystems and Environment, 256 (January), 200-210. https://doi.org/10.1016/j. agee.2018.01.012

Aznar, O., Marsat, J. B., y Rambonilaza, T. (2007). Tourism and landscapes within multifunctional rural areas: The French case. En K. Mander, Ülo, Wiggering, Hubert, Helming (Eds.), Multifunctional Land Use: Meeting Future Demands for Landscape Goods and Services (pp. 293-303). Berlín, Springer. https://doi.org/10.1007/978-3-540-36763-5 18

Bański, J. y Mazur, M. (2016). Classification of rural areas in Poland as an instrument of territorial policy. Land Use Policy, 54, 1-17. https://doi.org/10.1016/i.landusepol.2016.02.005

Barbieri, C. (2013). Assessing the sustainability of agritourism in the US: A comparison between agritourism and other farm entrepreneurial ventures. Journal of Sustainable Tourism, 21(2), 252-270. https://doi.org/10.1080/09669582.2012.685174

Barbieri, C., Sotomayor, S., y Aguilar, F. (2016). Perceived Benefits of Agritourism : A Comparison between Missouri Metropolitan and Non- Metropolitan Residents. Tourism Travel and Research Association: Advancing Tourism Research Globally, 59. Recuperado de https://scholarworks.umass.edu/ttra/2011/Visual/59/

Barbieri, C., Xu, S., Gil-Arroyo, C., y Rich, S. R. (2015). Agritourism, Farm Visit, or.. ? A Branding Assessment for Recreation on Farms. Journal of Travel Research, 55(8), 1094-1108. https://doi.org/10.1177/0047287515605930

Barreiro, J., Casado, J.M., Pérez y Pérez, L., y Muñoz Yanguas, M.A. (2003). Valoración de las Especies y Espacios Protegidos en Aragón. Evidencia en un Modelo Spike e inclusión de las Preferencias Inciertas en un Modelo de Valoración Contingente. Comunicación presentada en el VI Encuentro De Economía Aplicada, Granada, 5-7 Junio, 2003.

Belova, A. V., y Kropinova, E. G. (2015). New Forms of Innovative Tourism Products as a Result of the Interaction of History, Culture and Tourism. Mediterranean, Journal of Social Sciences, 6(6), 41-45. https://doi.org/10.5901/mjss.2015.v6n6s7p41 
Bessiere, J., y Tibere, L. (2013). Traditional food and tourism: French tourist experience and food heritage in rural spaces. Journal of the Science of Food and Agriculture, 93(14), 3420-3425. https://doi.org/10.1002/jsfa.6284

Bimonte, S., y Faralla, V. (2012). Tourist types and happiness a comparative study in Maremma, Italy. Annals of Tourism Research, 39(4), 1929-1950. https://doi.org/10.1016/i. annals.2012.05.026

Brandth, B. y Haugen, M. S. (2011). Farm diversification into tourism - Implications for social identity?. Journal of Rural Studies, 27(1), 35-44. https://doi.org/10.1016/i. jrurstud.2010.09.002

Brunori, G., y Rossi, A. (2007). Differentiating countryside: Social representations and governance patterns in rural areas with high social density: The case of Chianti, Italy. Journal of Rural Studies, 23(2), 183-205. https://doi.org/10.1016/i.jrurstud.2006.10.001

Carmichael, B. A. (2005). Understanding the wine tourism experience for winery visitors in the Niagara region, Ontario, Canada. Tourism Geographies, 7(2), 185-204. https://doi. org/10.1080/14616680500072414

Carneiro, M. J., Lima, J., y Silva Lavrador, A. (2015). Landscape and the rural tourism experience: identifying key elements, addressing potential, and implications for the future. Journal of Sustainable Tourism, 23(8-9), 1217-1235. https://doi.org/10.1080/0966958 $\underline{2.2015 .1037840}$

Cassia, F., Bruni, A., y Magno, F. (2015). Heritage preservation: is it a motivation for agritourism entrepreneurship?. XXVII Convegno Annuale Di Sinergie Heritage, Management e Impresa: Quali Sinergie? (pp. 565-574). https://doi.org/10.7433/SRECP.2015.34

Cavaco, C. (2005). As Paisagens Rurais : Do ‘ Determinismo Natural. Finisterra, XI, 73-101.

Ciervo, M. (2013). Agritourism in Italy and the local impact referring to Itria Valley. The organic firm "raggio verde" and its ecological agritourism project. European Countryside, 5(4), 322-338. https://doi.org/10.2478/euco-2013-0021

Clarke, J. (1996). Farm accommodation and the communication mix. Tourism Management, 17(8), 611-616. https://doi.org/10.1016/S0261-5177(97)84224-0

Colombo, S., y Calatrava, J. (2004). A socioeconomic approach to account for off-site effects of soil erosion. Rev. Advances in agroecology, 26, 1-9.

Comen, T. (2017). Agritourism Stories Critical Success Factors for Agritourism Entrepreneurs. 2nd International Congress on Marketing, Rural Development, and Sustainable Tourism, 1, 1-7.

Covas, A. (2011) - Futuros do mundo rural português: De espaço produtor a espaço produzido: mercados emergentes e neo-rurais. En Figueiredo, E., Kastenholz, E., Eusébio, E., Gomes, C., Carneiro, M. J., Batista, P., Valente, S. (Eds.) O Rural Plural-Olhar o presente, imaginar o futuro. (pp. 59-70). Castro Verde. 100 Luz.

Cunha, A. (Ed.). (2004) - A política agrícola comum na era da globalização. Almedina: Coimbra.

Chen, B., QIU, Z. y NAKAMURA, K. (2016). Tourist preferences for agricultural landscapes: a case study of terraced paddy fields en Noto Peninsula, Japan. Journal of Mountain Science, 13(10), 1880-1892. https://doi.org/10.1007/s11629-015-3564-0

Choenkwan, S., Promkhambut, A., Hayao, F., y Rambo, A. T. (2016). Does Agrotourism Benefit Mountain Farmers? A Case Study in Phu Ruea District, Northeast Thailand. 
Mountain Research and Development, 36(2), 162-172. https://doi.org/10.1659/ MRD-JOURNAL-D-15-00111.1

Daniel, T. C., Muhar, A., Arnberger, A., Aznar, O., Boyd, J. W., Chan, K. M. A., ... von der Dunk, A. (2012). Contributions of cultural services to the ecosystem services agenda. Proceedings of the National Academy of Sciences, 109(23), 8812-8819. https://doi.org/10.1073/ pnas.1114773109

Davies, E. T., y Gilbert, D. C. (1992). A case study of the development offarm tourism in Wales. Tourism Management, 13, 56-63. https://doi.org/10.1016/0261-5177(92)90033-4

Davis, P., y Corsane, G. (2014). Communities, heritage and new culture landscape. En M. Roe, y K. T. (Eds), New cultural landscapes (pp. 118-135). Abingdon UK: Routledge.

De Montis, A., Ledda, A., Serra, V., Noce, M., Barra, M., y De Montis, S. (2017). A method for analysing and planning rural built-up landscapes: The case of Sardinia, Italy. Land Use Policy, 62, 113-131. https://doi.org/10.1016/j.landusepol.2016.12.028

Di Domenico, M. L., y Miller, G. (2012). Farming and tourism enterprise: Experiential authenticity in the diversification of independent small-scale family farming. Tourism Management, 33(2), 285-294. https://doi.org/10.1016/j.tourman.2011.03.007

Dou, Y., Zhen, L., Yu, X., Bakker, M., Carsjens, G. J., y Xue, Z. (2019). Assessing the influences of ecological restoration on perceptions of cultural ecosystem services by residents of agricultural landscapes of western China. Science of the Total Environment, 646, 685695. https://doi.org/10.1016/i.scitotenv.2018.07.205

Duarte Alonso, A. (2010). Olives, hospitality and tourism: a Western Australian perspective. British Food Journal, 112(1), 55-68. https://doi.org/10.1108/00070701011011209

ELC (2000). European Landscape Convention. Florence, 20/10/2000 - Treaty open for signature by the member States of the Council of Europe and for accession by the European Union and the European non-member States. CETS No.176, Recuperado de https:// www.coe.int/en/web/landscape

Fawcett, S. L. (1996). Quality in the Agri-Tourism Product. Progress. Tourism and Hospitality Research, 2, 79-86. https://doi.org/10.1002/(SICl)1099-1603 (199603)2:1<79::AID-PTH25>3.0.CO;2-K

Figueiredo, E. (2009). One Rural, Two Visions. Environmental Issues and Images. European Countryside, 1, 9-21. https://doi.org/10.2478/v10091/009-0002-8

Flanigan, S., Blackstock, K. y Hunter, C. (2014). Agritourism from the perspective of providers and visitors: A typology-based study. Tourism Management, 40, 394-405. https://doi. org/10.1016/i.tourman.2013.07.004

Gao, J., Barbieri, C. y Valdivia, C. (2013). Agricultural Landscape Preferences. Journal of Travel Research, 53(3), 366-379. https://doi.org/10.1177/0047287513496471

García, B. (2005). Características Diferenciales Del Producto Turismo Rural. Cuadernos de Turismo, 15, 113-133.

Gil Arroyo, C., Barbieri, C., y Rozier Rich, S. (2013). Defining agritourism: A comparative study of stakeholders' perceptions in Missouri and North Carolina. Tourism Management, 37, 39-47. https://doi.org/10.1016/i.tourman.2012.12.007

Gobierno de España. (2014). Programa de desarrollo rural sostenible. Situación y diagnóstico del medio rural en España. 4-5, Recuperado de https://www.mapa.gob.es/es/ 
desarrollo-rural/planes-y-estrategias/ley-para-el-desarrollo-sostenible-del-medio-rural/prog-desarrollo-rural-sostenible/.

Gómez-Limón, J.A., y Barreiro-Hurlé, J. (2007). Valoración de bienes ambientales complejos: una alternativa multicriterio. Economía Agraria y Recursos Naturales, 7(14), 83-107.

Guzel, B., y Apaydin, M. (2016). Gastronomy Tourism: Motivations and Destinations. En Avcıkurt, C., Dinu, M. S, Hacıoğlu, N., Efe, R., Soykan, A., Tetik, N. (Eds.) Global Issues and Tends in Tourism (pp. 394-404). Sofía. ST. KLIMENT OHRIDSKI UNIVERSITY PRESS

Hall, C. M., y Sharples, L. (2003). The consumption of experiences or the experience of consumption? An introduction to the tourism of taste. En B. C. C. Michael Hall, Liz Sharples, Richard Mitchell, Niki Macionis (Eds.), Food Tourism Around The World (pp. 1-24). https://doi.org/10.1016/b978-0-7506-5503-3.50004-x

Hanson, J., y Bell, M. (2007). Harvest trails in Australia: patterns of seasonal migration in the fruit and vegetable industry. Journal of Rural Studies, 23(1), 101-117

Hashimoto, A., y Telfer, D. J. (2010). Developing sustainable partnerships in rural tourism: The case of oita, japan. Journal of Policy Research in Tourism, Leisure and Events, 2(2), 165183. https://doi.org/10.1080/19407963.2010.482276

Hermans, D. (1981). The encounter of agriculture and tourism a Catalan case. Annals of Tourism Research, 8(3), 462-479. https://doi.org/10.1016/0160-7383(81)90009-8

Hernández Hernandez, M. y Moltó Mantero, E. (2000). La agricultura en la montaña de Alicante: situación actual y potencial futuro. Investigaciones geográficas, 24, 55-68.

Hernández-Mogollón, J. M., Di-Clemente, E. y López-Guzman, T. (2015). El turismo gastronómico como experiencia cultural. El caso práctico de la ciudad de Cáceres (España). Boletín de La Asociación de Geógrafos Españoles, 68, 407-428. Recuperado de https:// bage.age-geografia.es/ojs//index.php/bage/article/view/1868/1784

Hjalager, A.-M. (1996). Agricultural diversification into tourism. Tourism Management, 17(2), 103-111. https://https://doi.org/10.1016/0261-5177(95)00113-1

Hüller, S., Heiny, J. y Leonhäuser, I.-U. (2017). Linking agricultural food production and rural tourism in the Kazbegi district. A qualitative study. Annals of Agrarian Science, 15(1), 40-48. https://https://doi.org/10.1016/i.aasci.2017.02.004

INE (2016). Encuesta sobre la estructura de las explotaciones agrícolas - Año 2016. Recuperado de https://ine.es/dyngs/INEbase/es/operacion. htm?c=Estadistica C\&cid=1254736176854\&menu=ultiDatos\&idp=1254735727106

INE (2018). Demografía y población. Recuperado de https://ine.es/dyngs/INEbase/es/categoria.htm?c=Estadistica P\&cid=1254734710984

INE (2018a). Estatísticas do Turismo - 2017. Recuperado de https://www.ine.pt/xportal/ $\underline{\text { xmain? }}$ xpid=INE\&xpgid=ine indicadores\&contecto=pi\&indOcorrCod=0008273\&selTa$\underline{\mathrm{b}=\mathrm{tab} 0}$

INE (2018b). Indicadores de población y território. Recuperado de https://www.ine.pt/xportal/ xmain?xpid=INE\&xpgid=ine indicadores\&contecto=pi\&indOcorrCod=0008273\&selTa$\underline{b=t a b 0}$

Kastenholz, E., Carneiro, M. J., Peixeira Marques, C., y Lima, J. (2012). Understanding and managing the rural tourism experience - The case of a historical village in Portugal. Tourism Management Perspectives, 4, 207-214. https://doi.org/10.1016/i.tmp.2012.08.009 
Kiryluk-Dryjska, E., y Baer-Nawrocka, A. (2019). Reforms of the Common Agricultural Policy of the EU: Expected results and their social acceptance. Journal of Policy Modeling, 41(4), 607-622. https://doi.org/10.1016/j.jpolmod.2019.01.003

Kline, C., Barbieri, C., y LaPan, C. (2015). The Influence of Agritourism on Niche Meats Loyalty and Purchasing. Journal of Travel Research, Published online January 2, doi:10.1177/0047287514563336.

Kuo, N.-W., Chen, Y.-J., y Huang, C.-L. (2008). Linkages between organic agriculture and agro-ecotourism. Renewable Agriculture and Food Systems, 21(04), 238-244. https:// doi.org/10.1079/raf2006148

Lapan, C., y Barbieri, C. (2014). The role of agritourism in heritage preservation. Current Issues in Tourism, 17(8), 666-673. https://doi.org/10.1080/13683500.2013.849667

Ley 45/2007, de 13 de diciembre para el Desarrollo Sostenible del Medio Rural, BOE, 14 de diciembre de 2007.

Ley 48/98, de 11 de agosto, Bases de la política de la ordenación del territorio y urbanismo, revocada por la Ley n. 0 31/2014, de 30 de Mayo.

Luís, E. (2002). Turismo no espaço rural em Portugal: um apontamento introdutório. Geolnova, 5, 139-152.

Madureira, L., Gamito, T., M; Ferreira, D., y Portela, J. (2013). Inovação em Portugal Rural. Detetar, Medir e Valorizar. Ed. 1. Lisboa. Princípia.

Massot, A. (2003). La Reforma de la PAC 2003: hacia un modelo de apoyo para las explotaciones agrarias. Revista de Estudios Agrosociales y Pesqueros, 199, 11-60.

Massot, A. (2004). "Quo Vadis PAC?": una propuesta reformista a favor de una nueva Política Agro-rural Común. V Congreso Asociación Española de Economía Agraria. Santiago de Compostela (España).

Mastronardi, L., Giaccio, V., Giannelli, A., y Scardera, A. (2015). Is agritourism eco-friendly? A comparison between agritourisms and other farms in italy using farm accountancy data network dataset. SpringerPlus, 4(1), 1-12. https://doi.org/10.1186/s40064-015-1353-4

Mcgehee, N. G. (2007). An agritourism systems model: A Weberian perspective. Journal of Sustainable Tourism, 15(2), 111-124. https://doi.org/10.2167/jost634.0

Molinero Hernando, F. (2011): Paisajes y economías agrarias: del policultivo de subsistencia a la especialización agraria mundial; En Leco Berrocal, F.; Pérez Díaz, A. y Mateos Rodríguez, B. (coords.): XV Coloquio de Geografía Rural. Geografía y Desarrollo Rural. Territorio, Paisaje y Patrimonio. Ponencias, Ministerio de Medio Ambiente y Medio Rural y Marino-Confederación Hidrográfica del Guadiana, Cáceres, 2011; pp. 5-56.

Moltó Mantero, E. y Hernández Hernández, M. (2004). La funcionalidad de los medios rurales en las sociedades urbanas. Investigaciones Turísticas, 34, 63-76.

Nazariadli, S., Morais, D. B., Barbieri, C., y Smith, J. W. (2018). Does perception of authenticity attract visitors to agricultural settings?. Tourism Recreation Research, 43(1), 91-104. https://doi.org/10.1080/02508281.2017.1380144

Nekhay, O. y Arriaza, M. (2016). How attractive is upland olive groves landscape? Application of the analytic Hierarchy Process and gis in southern Spain. Sustainability (Switzerland), 8(11), 1160. https://doi.org/10.3390/su8111160

Palmer, C. (1999). Tourism and the symbols of identity. Tourism Management, 20, 313-321. doi:10.1016/S0261-5177(98) 00120-4 
Pavletic, M. (2015). Tourism and Organic Food Production in Croati : Case Study of the Cetina Region (Tesis de Maestría). Western Michigan University.

Petroman, C., y PET, I. (2017). Farm Agrotourism Alternative Sources of Income in Rural Area, Scientific Papers Animal Science and Biotecnhologies, 50(1), 285-288.

Phillip, S., Hunter, C., y Blackstock, K. (2010). A typology for defining agritourism. Tourism Management, 31(6), 754-758. https://doi.org/10.1016/i.tourman.2009.08.001

Pillay, M., y Rogerson, C. M. (2013). Agriculture-tourism linkages and pro-poor impacts: The accommodation sector of urban coastal KwaZulu-Natal, South Africa. Applied Geography, 36, 49-58. https://doi.org/10.1016/i.apgeog.2012.06.005

Plaza Gutiérrez, J. I. (2016). El valor patrimonial de los paisajes rurales. Algunos ejemplos. En Rebollo, J. F., Cantos, J. O., Hérnadez Hérnadez, M., Morales Gil, A. (Coord.), Paisage, cultura territorial y vivencia de la Geografía. Libro Homenaje al Profesor Alfredo Morales Gil (pp. 343-360). Universitat d'Alacant / Universidad de Alicante, Instituto Interuniversitario de Geografía.

Przezb, L. (2004). Identification of Rural and Agri-Tourism. Roczniki Akademii Rolniczej w Poznaniu - CCCLIX, 3, 165-177.

Pulido Fernández, J. I., y Cárdenas García, P. (2011). El turismo rural en España. Orientaciones estratégicas para una tipología aún en desarrollo. Boletín de La Asociación de Geógrafos Españoles, 56, 155-176. Recuperado de https://bage.age-geografia.es/ojs/index.php/ bage/article/view/1348/1271

Ramírez, E. D. (2015). Agroecoturismo: aportes para el desarrollo de una tipología turística en el contexto latinoamericano. Turismo y Sociedad, 15. 223-236 https://doi. org/10.18601/01207555.n15.13

Randelli, F., Romei, P., y Tortora, M. (2014). An evolutionary approach to the study of rural tourism: The case of Tuscany. Land Use Policy, 38, 276-281. https://doi.org/10.1016/j. landusepol.2013.11.009

Riguccio, L., Tomaselli, G., Russo, P., y Falanga, C. (2015). Identification of "Typical Agricultural Districts" for the development of rural areas applied to Eastern Sicily. Land Use Policy, 44, 122-130. https://doi.org/10.1016/i.landusepol.2014.11.018

Salvado, J. (2016). Wine Culture, Territory/Landscape and Tourism, the Enotourism Key Pillars. How To Get Business Success and Territorial Sustainability Inside Wine Tourism Ecosystem? A Pathway for the New Generation of Tourism Research. Proceedings of the EATSA Conference 2016, 391-414.

Sánchez-Cañizares, S. M., y López-Guzmán, T. (2012). Gastronomy as a tourism resource: Profile of the culinary tourist. Current Issues in Tourism, 15(3), 229-245. https://doi.org $\angle 10.1080 / 13683500.2011 .589895$

Santich, B. (2004). The study of gastronomy and its relevance to hospitality education and training. International Journal of Hospitality Management, 23(1), 15-24.

Sayadi, S., y Calatrava-Requena, J. (2001). Agroturismo y desarrollo rural: situación actual, potencial y estrategias en zonas de montaña del sureste español. Cuadernos de Turismo, 7, 131-157. Recuperado de https://revistas.um.es/turismo/article/view/22091

Sayadi, S., González-Roa, M. C., y Calatrava-Requena, J. (2009). Public preferences for landscape features: The case of agricultural landscape in mountainous Mediterranean areas. Land Use Policy, 26(2), 334-344. https://doi.org/10.1016/i.landusepol.2008.04.003 
Sengel, T., Karagoz, A., Cetin, G., Istanbullu Dincer, F., Ertugral, S. M., y Balik, M. (2015). Tourists' Approach to Local Food. Procedia. Social and Behavioral Sciences, 195, 429437. https://doi.org/10.1016/j.sbspro.2015.06.485

Sidali, K. L., Kastenholz, E., y Bianchi, R. (2015). Food tourism, niche markets and products in rural tourism: combining the intimacy model and the experience economy as a rural development strategy. Journal of Sustainable Tourism, 23(8-9), 1179-1197. https://doi. org/10.1080/09669582.2013.836210

Sims, R. (2009). Food, place and authenticity: Local food and the sustainable tourism experience. Journal of Sustainable Tourism, 17(3), 321-336. https://doi. org/10.1080/09669580802359293

Streifeneder, T. (2016). Agriculture first: Assessing European policies and scientific typologies to define authentic agritourism and differentiate it from countryside tourism. Tourism Management Perspectives, 20, 251-264. https://doi.org/10.1016/j.tmp.2016.10.003

Sznajder, M., Przezborska, L. y Scrimgeour, F. (2009). Agritourism. Wallingford: CABI.

Tew, C., y BARBIERI, C. (2012). The perceived benefits of agritourism: The provider's perspective. Tourism Management, 33(1), 215-224. https://doi.org/10.1016/j.tourman.2011.02.005

Thompson, M., Prideaux, B., Mcshane, C., Dale, A., Turnour, J., y Atkinson, M. (2016). Tourism development in agricultural landscapes: the case of the Atherton Tablelands, Australia. Landscape Research, 41(7), 730-743. https://doi.org/10.1080/01426397.2016.11748 $\underline{39}$

Torres, R. (2003). Linkages between tourism and agriculture in Mexico. Annals of Tourism Research, 30(3), 546-566. https://doi.org/10.1016/S0160-7383(02)00103-2

Torres, R. y Momsen, J. H. (2004). Challenges and potential for linking tourism and agriculture to achieve pro-poor tourism objectives. Progress in Development Studies, 4(4), 294318. https://doi.org/10.1191/1464993404ps092oa

Uğurlu, K. (2014). Organic tourism as a tool to raise healthy tourism destinations: an investigation in Turkey. Applied Studies in Agribusiness and Commerce, 8(4), 69-77. Recuperado de https://r.search.yahoo.com/_ylt=AwrJQ543Y8BddW0AMz1U04IQ; ylu=X3oDMTByaW11dnNvBGNvbG8DaXIyBHBvcwMxBHZOaWQDBHNIYwNzcg--/ $\mathrm{RV}=2 / \mathrm{RE}=1572918199 / \mathrm{RO}=10 / \mathrm{RU}=\mathrm{http} \% 3 \mathrm{a} \% 2 \mathrm{f} \% 2 \mathrm{fageconsearch} . \mathrm{umn}$. edu\%2fbitstream\%2f210467\%2f2\%2f11 Kaplan.pdf/RK=2/RS=pD.byv. Xrp4000wWjac1ysiTUls-

Van Der Ploeg, J.D. y Roep, D. (2003). Multifunctionality and rural development: the actual situation in Europe». En Van Huylenbroeck, G., Van Durand, G., y Aldershot, Ashgate (Eds.), Multifunctional Agriculture: A New Paradigm for European Agriculture and Rural Development (pp. 37-54). Ashgate. Wiley Online.

Wang, Y., Rompf, P., Severt, D., y Peerapatdit, N. (2006). Examining and identifying the determinants of travel expenditure patterns. International Journal of Tourism Research, 8(5), 333-346. https://doi.org/10.1002/jtr.583 